\title{
Biologically plausible statistics from a Markov model of spiking cortical networks
}

\author{
Marc Benayoun*1, Edward Wallace ${ }^{2}$, Tanya Baker ${ }^{3}$, Jack Cowan ${ }^{2}$ and \\ Wim van Drongelen ${ }^{1}$
}

Address: ${ }^{1}$ Department of Pediatrics, University of Chicago, Chicago, IL 60637, USA, ${ }^{2}$ Department of Mathematics, University of Chicago, Chicago, IL 60637, USA and ${ }^{3}$ The Salk Institute for Biological Studies, La Jolla, CA 92037, USA

Email: Marc Benayoun* - marcb@uchicago.edu

* Corresponding author

from Seventeenth Annual Computational Neuroscience Meeting: CNS*2008

Portland, OR, USA. 19-24 July 2008

Published: II July 2008

BMC Neuroscience 2008, 9(Suppl I):P38 doi:10.1 I86/I47I-2202-9-SI-P38

This abstract is available from: http://www.biomedcentral.com/I47I-2202/9/SI/P38

(C) 2008 Benayoun et al; licensee BioMed Central Ltd.

\section{Background}

Understanding the spatio-temporal correlations observed in nervous tissue is a major challenge in computational neuroscience. We approach this challenge by modeling the global network state as a single Markov process $[1,2]$. Each neuron is modeled as a two (active or inactive) - or three-state (active, inactive, or refractory) random variable, with each neuron's spike probability a function of its input current and internal threshold, updated at time

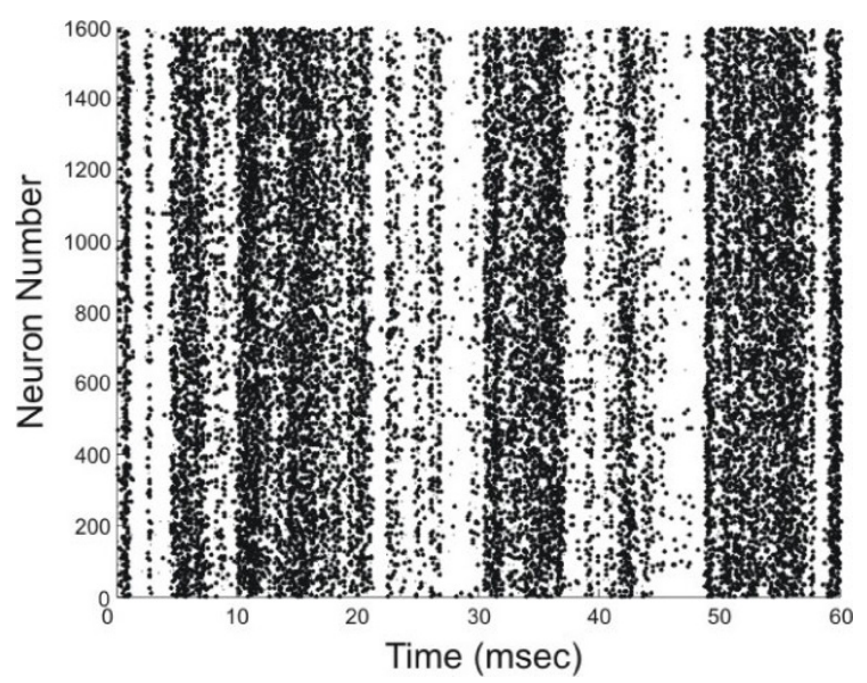

Figure I

Raster Plot. steps dependent upon the current network state. Using the stochastic simulation algorithm [3], we simulate the network model with excitatory and inhibitory neurons and with random connectivity tuned so that each spike triggers on average one new spike, i.e. in the critical regime.

In order to study the model analytically, we recast the model in the language of statistical field theory [2]. The

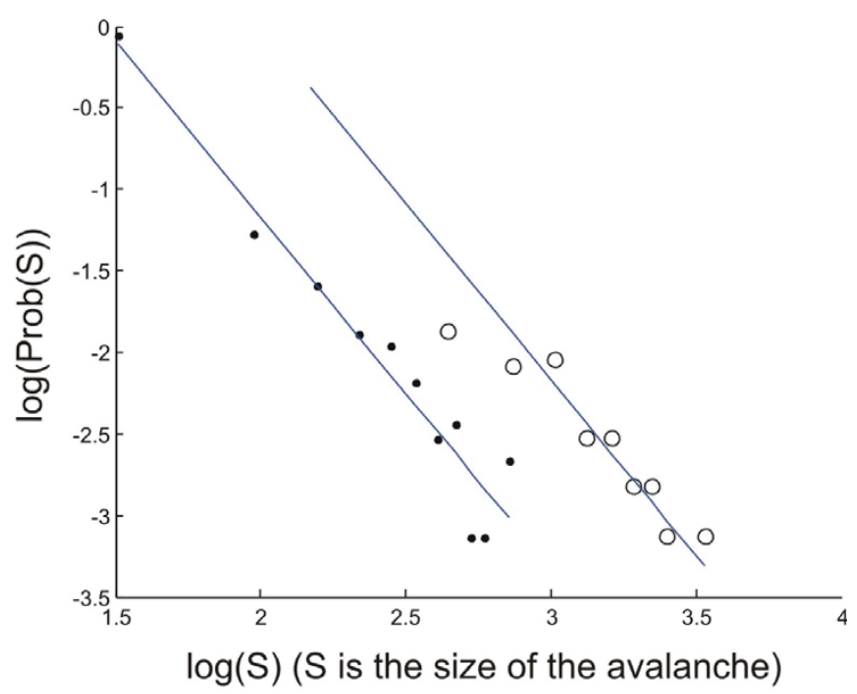

Figure 2

Model size distribution. 


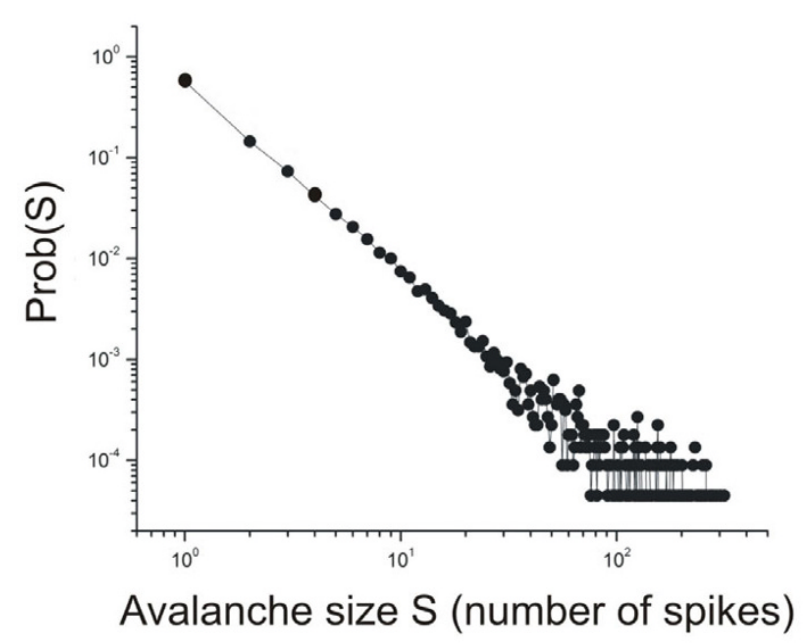

Figure 3

Experimental size distribution.

result is a moment-generating functional which permits the calculation of correlation functions and critical exponents. Analytical calculation of the first moment produces a form of the Wilson-Cowan equations [4]. The analytical and simulation results can be compared to those obtained from cortical slice recordings [5].

\section{Conclusion}

Figure 1 shows that model simulations produce spike trains, as part of highly variable, correlated, network activity resembling the "neuronal avalanches" observed in cortical slice tissue [5]. The simulations reveal a power-law distribution of avalanche sizes with a critical exponent of -2.15 when a 900 neuron network is simulated (data set represented by dots in Figure 2) and -2.168 when a 1600 neuron network is simulated (data set represented by circles in Figure 2). These compare well with the critical exponents calculated from unsorted spike data taken from multiunit recordings. Figure 3 shows one such experiment, where the critical exponent was calculated to be 2.14 .

\section{Acknowledgements}

This work was supported in part by the Falk Foundation and the Linn family. Also, we would like to thank Dr. John Beggs, Dr. Alan Litke, and Aonan Tang for providing the experimental data on critical exponents and Figure 3.

\section{References}

I. Cowan JD: Stochastic neurodynamics. Proc of the 1990 conf on adv in neural inf process sys 3 1990:62-69.

2. Buice MA, Cowan JD: Field-theoretic approach to fluctuation effects in neural networks. Phys Rev E 2007, 75(5):051919.

3. Gillespie DT: Exact stochastic simulation of coupled chemical reactions. J Phys Chem 1977, 8 I(25):2340-236I.
4. Wilson HR, Cowan JD: Excitatory and inhibitory interactions in localized populations of model neurons. Biophys J. 1972, I 2(I): I-24.

5. Beggs JM, Plenz D: Neuronal avalanches in neocortical circuits. J Neurosci 2003, 23(35): I I I67-III 177.

\section{Publish with Bio Med Central and every scientist can read your work free of charge}

"BioMed Central will be the most significant development for disseminating the results of biomedical research in our lifetime. "

Sir Paul Nurse, Cancer Research UK

Your research papers will be:

- available free of charge to the entire biomedical community

- peer reviewed and published immediately upon acceptance

- cited in PubMed and archived on PubMed Central

- yours - you keep the copyright

Submit your manuscript here:

http://www.biomedcentral.com/info/publishing_adv.asp 